\title{
Lipopolysaccharide Induces IL-6 Production in Respiratory Syncytial Virus-Infected Airway Epithelial Cells Through the Toll-Like Receptor 4 Signaling Pathway
}

\author{
XIAO-HONG XIE, HELEN K.W. LAW, LI-JIA WANG, XIN LI, XI-QIANG YANG, AND EN-MEI LIU
}

\begin{abstract}
Immunological Laboratory of Children Research Center [X.-H.X., L.-J.W.], Core Laboratory of Children Research Center [X.L.], Department of Nephrology and Immunology [X.-Q.Y.], Division of Respiratory Medicine [E.-M.L.], Children's Hospital of Chongqing Medical University, Chongqing 400014, People's Republic of China; Department of Paediatrics and Adolescent Medicine [H.K.L.], University of Hong Kong, Hong Kong, People's Republic of China
\end{abstract}

\begin{abstract}
Respiratory syncytial virus (RSV) is a leading cause of bronchiolitis in young children. Microbial agents such as endotoxin and RSV are implicated in airway inflammation during the development of reactive airway disease (RAD) later in childhood. Toll-like receptors (TLRs) are involved in an inflammation cascade through pathogen-associated molecular pattern recognition including lipopolysaccharide (LPS) and viral components. In this study, we investigated the expression of TLRs and cytokine-chemokine production profiles of RSV-infected epithelial cells. In live-RSV infected human tracheal epithelial cell line (9HTEo), TLRs 1-10 mRNA levels were up-regulated in a time-dependent manner compared with ultraviolet (UV)-inactivated RSV. RSV was shown to alter TLR4 membrane and cytosolic location in epithelial cells. Stimulating RSV-infected epithelial cells with TLR4 agonist LPS increased synthesis of IL-6, IL-8, and reduced regulated on activation, normal $\mathrm{T}$ cell expressed and secreted (RANTES) production. TLR4 neutralizing antibody HTA125 and TLR4-targeting RNA interference experiments revealed that TLR4 signaling pathway played a predominant role in mediating LPS-induced-IL-6 production of RSV infected epithelial cells. Altogether, our studies indicated that TLR4 play a critical role in leading LPS mediated-IL-6 response in RSV infected-epithelial cells and might be an important factor influencing the cytokine-chemokine profile of epithelial cells interacting with virus and endotoxin, which is correlated with phenotypes of RSV diseases. (Pediatr Res 65: 156-162, 2009)
\end{abstract}

$\mathrm{R}$ espiratory syncytial virus (RSV) is the major cause of lower respiratory tract disease in infants and young children worldwide. Children who have recovered from RSV bronchiolitis are at increased risks to reactive airway disease (RAD) such as recurrent wheezing or persistent wheezing in later childhood. Although there is increasing evidence that the host response to RSV infection is a combined function of genetic background, exposure to environmental antigens, the degree of maturation of the host's immune system and airway at the time of the infection (1), the mechanisms and signaling

Received May 9, 2008; accepted September 12, 2008.

Correspondence: En-mei Liu, M.D., Ph.D., Division of Respiratory Medicine, Children's Hospital of Chongqing Medical University, Chongqing 400014, People's Republic of China; e-mail: emliu186@hotmail.com

This work was funded by National Nature Science Foundation of China (30300321), Program for New Century Excellent Talents in University (NCET-06-0775), and Foundation of Bureau of Public Health of Chongqing (04-1-005). pathways of RSV-induced RAD are still not completely understood.

Mammalian toll-like receptors (TLRs), homologues of Drosophila Toll proteins are indispensable molecules at recognizing the pathogen-associated molecular pattern (PAMP) of invasive agents (2-4). One of the most fundamental TLRmediated effects is to activate NF- $\kappa \mathrm{B}$ members and monitor subsequent proinflammatory cytokines or chemokines production, which are strongly associated with the outcome of inflammatory disease. As a member of the Paramyxoviridae family, RSV consists of a negative-strand RNA genome in a nucleocapsid surrounded by one envelope, and a number of TLRs are supposed to recognize these components, including TLR3 (double-stranded RNA), TLR4 (binding to F-protein of RSV), TLR7/8 (single-stranded RNA), and TLR9 (DNA as unmethylated $\mathrm{CpG}$ motif) (5-8).

Respiratory epithelium has emerged as a major origin of airway inflammation, because it is the primary site for RSV entry and replication. A new paradigm called the Epithelial -ViralAllergic, formally presented by Holtzman et al. (9), has described the important roles of airway epithelium, paramyxovirus and allergen in airway inflammation. Cytokines and chemokines, secreted by airway epithelial cells, play a critical role in regulating local inflammatory processes in the lung and may arise as a result of excessive activation of TLRs by pathogen recognition. Some studies have found that TLR1-10 are constitutively expressed in the respiratory epithelial cells $(2,10-12)$, and Monick et al. (13) reported that RSV could sensitize airway epithelial cells to endotoxin exposure by releasing IL-8 through TLR4 pathway, although un-infected epithelial cell were quite tolerant to lipopolysaccharide (LPS) challenge.

In this study, we evaluated the effect of RSV on TLR1-10 mRNA expression in tracheal epithelial cells and determined the relevance of epithelial TLR4 in mediating inflammation in

Abbreviations: DC, dendritic cell; FCS, fetal calf serum; LPS, lipopolysaccharide; MOI, multiplicity of infection; PAMP, pathogen-associated molecular pattern; polyIC, polyriboinosinic:polyribocytidylic acid; PMN, polymorphonuclear neutrophil leukocyte; RSV, respiratory syncytial virus; RAD, reactive airway disease; TLRs, toll-like receptors; Treg, regulatory T cell; UV, ultraviolet 
the RSV-LPS co-existing system. RSV induces epithelialdependent IL-8, IL-6, and regulated on activation, normal T cell expressed and secreted (RANTES) secretion in its acute state (14), and we hypothesized that the cytokine-chemokine secretion profile of epithelial cells, characterized by RSVinduced TLR4 signaling pathway leading to IL-6 response after endotoxin exposure, might be an important aspect in RSV-induced RAD according to the possible pathogenesis.

\section{METHODS}

Epithelial cell culture. The human tracheal epithelial cell line (9HTEo) was derived from human tracheal epithelium and received as a gift from Professor Hans D. Ochs (University of Washington School of Medicine, Seattle, Washington). It was grown as a monolayer in RPMI 1640 (GIBCO, USA), supplemented with $10 \%$ heat-inactivated fetal calf serum (FCS), $2 \mathrm{mM}$ L-glutamine, $100 \mathrm{U} / \mathrm{mL}$ penicillin, $100 \mu \mathrm{g} / \mathrm{mL}$ streptomycin at $37^{\circ} \mathrm{C}$ with $5 \%$ $\mathrm{CO}_{2}$ in humidified air. Endotoxin contamination of the media used in subsequent experiments was below $0.25 \mathrm{ng} / \mathrm{mL}$.

$R S V$ propagation and titer determination. Viral stock of human RSV A2-strain was obtained from Viral Laboratory in Beijing Children's Hospital (Capital University of Medical Sciences, Beijing, China). RSV and ultraviolet (UV) light-inactivated RSV was prepared as previously described (13) Multiplicity of infection (MOI) was 10 in the subsequent experiments.

Quantification of toll-like receptor 1-10 RNA by RT-PCR and Real-Time Quantitative PCR. Cells $\left(\sim 2.5 \times 10^{5}\right)$ were harvested at 3,6 , and $9 \mathrm{~h}$ post RSV infection and total RNA was extracted by TRIzol Reagent (Invitrogen Life Technologies, USA). Reverse transcription was performed as previously described (15). First, standard PCR was performed in a total volume of $25 \mu \mathrm{L}$ and PCR conditions were $63^{\circ} \mathrm{C}$ for $60 \mathrm{~s}$ for 39 cycles. Second, synthesized cDNA was diluted (1:10) and quantified by real-time PCR using the Taqman Technology (Applied Biosystems, CA) as described previously (15). The $\beta$-actin gene was amplified as an internal control. Standard curves were generated using serial dilutions of plasmids $\left(\sim 10-10^{10}\right.$ copies $)$ containing cloned sequences. Results were calculated as the number of targeted molecules $/ \mu \mathrm{L}$ cDNA. To standardize results for variability in RNA and cDNA quantity and quality, we expressed the results as the number of target copies per $10^{4}$ copies of $\beta$-actin gene. The TLR1-10 specific primers and probes were modified from Sha et al. (2). $\beta$-actin primer and probes are as follows:

Forward: 5'-GGATGCAGAAGGAGATCACTG-3'

Reverse: 5'-CGATCCACACGGAGTACTTG-3'

Probe: 5'-CCCTGGCACCCA GCACAATG-3'

Flow cytometry analysis. RSV-infected and mock-infected cells $(2-3 \times$ $10^{5}$ ) were harvested at $24 \mathrm{~h}$ post RSV infection, and stained with PE anti-human Toll-like receptor 4 (Ebioscience, San Diego, CA) for $30 \mathrm{~min}$ at $4^{\circ} \mathrm{C}$. PE-labeled isotype antibody was used as control. For intracellular staining, cells were fixed with a solution of $3 \%$ paraformaldehye in phosphate buffered saline (PBS) for $10 \mathrm{~min}$ on ice and permeabilized by incubating a solution of $0.2 \%$ Tween 20 in PBS for $15 \mathrm{~min}$ at $37^{\circ} \mathrm{C}$. Fluorescence analysis was performed using a FACS Calibre machine with the FACScan software.

General LPS stimulation protocol and measurements of $I L-6, I L-8$, and RANTES by ELISA. In initial experiments, epithelial cells were cultured in RPMI $1640+10 \%$ FCS, supernatant was collected for IL-8 measurement and cells were harvested for cell count. Within 48 h, IL-8 levels were increased 4 -fold in the presence of serum. Therefore, to avoid the confounding effect of serum, cells were maintained in serum-free medium (RPMI 1640) $48 \mathrm{~h}$ before infection, and we conducted all the subsequent experiments under serum-free conditions as suggested in previous literature (16). Briefly, $1 \times 10^{5}$ cells were seeded in 24-well plate and grew for $48 \mathrm{~h}$ followed by inoculating with RSV for $12 \mathrm{~h}$ in serum-free medium. Infected cells were stimulated by $50 \mu \mathrm{g} / \mathrm{mL}$ LPS (Escherichia coli, serotype 0111:B4, Sigma Chemical, USA) alone or with $20 \mu \mathrm{g} / \mathrm{mL}$ anti-TLR4, HTA125 (AB30667, AbCam, USA) to $48 \mathrm{~h}$. Supernatants were collected, centrifuged at $14,000 \mathrm{rpm}$ for $10 \mathrm{~min}$ to remove cell debris, and stored at $-80^{\circ} \mathrm{C}$ for later analysis of IL-8, IL-6, and RANTES using sensitive ELISA kits obtained from Genzyme (USA) or R\&D systems (USA) according to manufacturer's instructions. Concentrations were normalized to $\mathrm{pg} / \mathrm{mL} / 10^{5}$ cells.

RNA interference in 9HTEo cells. Control nonsilencing siRNA (sense UUCUCCGAACGUGUCACGUTT, antisense ACGUGACACGUUCGGAGAATT) and siRNA targeting TLR4 (sense CCAGGUGCAUUUAAAGAAATT, antisense UUUCUUUAAAUGCACCUGGTT) were designed and purchased from Shanghai Benefit Biotechnology Co.LTD. 9HTEo cells were transfected by lipofectamin 2000 according to the manufacturer's protocol (Invitrogen, USA) with $150 \mathrm{nM}$ siRNA per $10^{5}$ cells. After $24 \mathrm{~h}$ RNA interfering, cells were inoculated by RSV and then treated with LPS as described previously. Supernatants were collected for ELISA detection of IL-8 and IL-6.

Statistical analysis. Statistical analysis was performed using GraphPad statistical analysis software. Significant differences were determined by paired $t$ test for RT-PCR results, Kruskal-Wallis test with Dunn's multiple comparison test for real-time PCR results, paired $t$ test, and Mann Whitney test for flow cytometry results and one-way repeated measures ANOVA with Newman-Keuls multiple comparison test for ELISA results. Differences were considered statistically significant at $p<0.05$.

\section{RESULTS}

TLRs expression pattern in 9HTEo cell line pre- and post-RSV priming. To determine the TLRs mRNA expression on 9HTEo cells, we first assessed the expression pattern by RT-PCR, further confirmed our results by quantitative realtime PCR and demonstrated that 9HTEo cells, similar to other respiratory cells lines reported (17), constitutively expressed TLR1-10 mRNA. TLR4 and TLR8 mRNA was higher at baseline expression in un-infected 9HTEo cells (Fig. 1A). All TLRs mRNA were significantly higher after $3 \mathrm{~h} \mathrm{RSV} \mathrm{infec-}$ tion except TLR1 by standard RT-PCR (Table 1). When infected with RSV for 6 or $9 \mathrm{~h}$, cells presented significant up-regulation of TLR 1-10 mRNA by quantitative PCR, and the pattern in infected cells was characterized by higher levels of TLR4 and TLR8 expression than others (Fig. $1 B-K$ ). The induction of the TLRs mRNA was dependent on viral transcription and replication, as there was no effect observed on cells treated by UV inactivated RSV at the same dose. These data showed that 9HTEo epithelial cells could express TLR1-10 mRNA, and RSV infection has an intensive effect on the epithelial TLRs mRNA expression, especially on TLR4 and TLR8. The observed increase in TLR1-10 mRNA levels by competent RSV priming suggested that RSV might mediate induction of the TLRs mRNA through enhanced mRNA production and/or mRNA stabilization.

TLR4 protein expression and localization in $9 H T E o$ cell line pre- and postRSV priming. Recent studies have shown that TLR4 of airway epithelial cells is primarily expressed in cytoplasm, and displayed weakly on the cell surface (18). Therefore, we determined both cytoplasmic and membrane TLR4 protein on un-infected cells by flow cytometry. As expected, TLR4 was mainly detected in the cell cytoplasm, and to a much lesser extent on the surface of cell (Fig. 2A). To determine whether the increase of TLR 4 mRNA observed by quantitative PCR is translated to protein expression, infected cells were stained with anti-human TLR4 antibody to examine TLR4 surface expression. Fixed and permeabilized cells were used to evaluate changes in cytoplasmic TLR4 expression. Comparable data (Fig. $2 B$ ) were obtained from a series of 10 independent experiments, and showed an almost $30 \%$ increase of TLR4 proteins on membranes (MOCK $0.970 \pm 0.46$ versus RSV1.268 $\pm 0.15, p=0.0404, n=10$ ) and only an $8 \%$ decrease of TLR4 protein in cytoplasm in the RSV-primed cells (MOCK $3.358 \pm 0.46$ versus $\mathrm{RSV} 3.084 \pm 0.49, p=$ $0.0225, n=8$ ). Figure $2 C$ shows a significantly higher percentage of membrane-TLR4 positive cells in RSVchallenged cell population by seven independent experiments. 

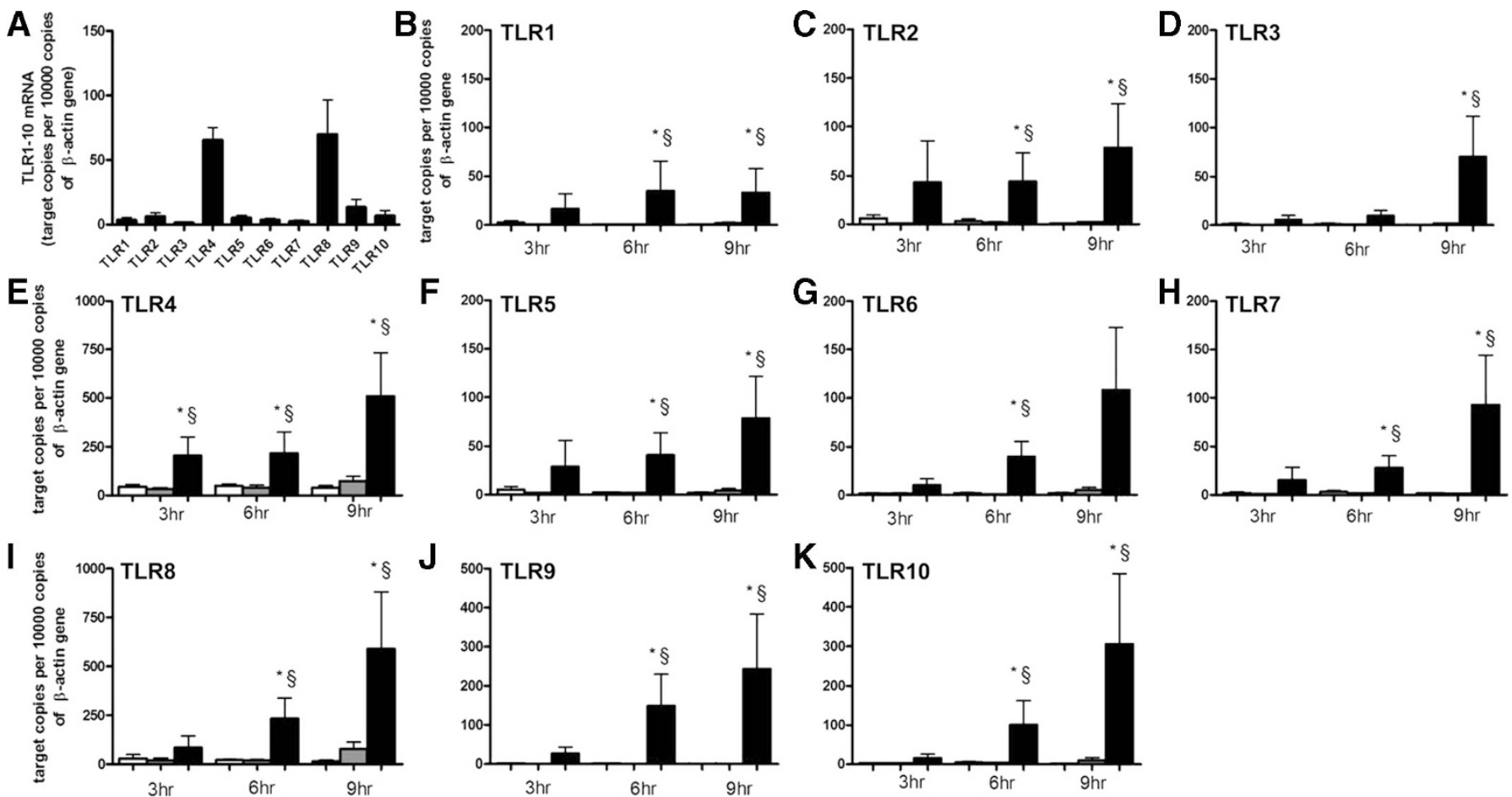

Figure 1. Quantitative real-time PCR analysis of TLR1-10 mRNA expression in 9HTEo cells before and after RSV infection. (A) TLRs mRNA expression in un-infected 9HTEo cells. ( $B$ to $K$ ) TLRs mRNA expression patterns after 3, 6, and $9 \mathrm{~h} \mathrm{RSV}$ and UV-inactivated RSV priming. Values expressed as mean \pm SEM, $n=4-6,{ }^{*} p<0.05 v s$. MOCK, $\$ p<0.05 v s$. UV-inactivated RSV. MOCK ( $\square$ ), UV-inactivated RSV ( $\square$ ), RSV

Table 1. Expression of TLR1-10 mRNA in RSV-infected 9HTEo cells by RT-PCR assay

\begin{tabular}{|c|c|c|c|c|}
\hline TLRs mRNA & $\operatorname{RSV}(n=3)$ & $\operatorname{MOCK}(n=3)$ & Paired student's $t$ test value & $p$ \\
\hline TLR1 & $1.91 \pm 0.84$ & $1.52 \pm 1.32$ & 0.648 & 0.5837 \\
\hline TLR2 & $31.11 \pm 8.27$ & $11.70 \pm 9.90$ & 4.598 & $0.0442 *$ \\
\hline TLR3 & $18.64 \pm 8.03$ & $11.75 \pm 4.16$ & 4.640 & $0.0434^{*}$ \\
\hline TLR4 & $38.39 \pm 13.41$ & $26.38 \pm 6.77$ & 3.488 & $0.0398 *$ \\
\hline TLR5 & $18.15 \pm 6.23$ & $9.21 \pm 3.34$ & 3.659 & $0.0353^{*}$ \\
\hline TLR6 & $22.25 \pm 9.24$ & $5.97 \pm 2.53$ & 6.988 & $0.0199 *$ \\
\hline TLR7 & $47.60 \pm 4.65$ & $18.74 \pm 4.77$ & 14.470 & $0.00477 * *$ \\
\hline TLR8 & $46.88 \pm 12.09$ & $26.55 \pm 3.49$ & 3.827 & $0.0314 *$ \\
\hline TLR9 & $39.88 \pm 16.93$ & $30.89 \pm 17.49$ & 9.420 & $0.0110 *$ \\
\hline TLR10 & $12.63 \pm 6.16$ & $7.90 \pm 1.80$ & 4.750 & $0.0422 *$ \\
\hline
\end{tabular}

Values of TLR1-10 mRNA/beta-actin mRNA were expressed as mean \pm SEM.

$* p<0.05, * * p<0.01$.
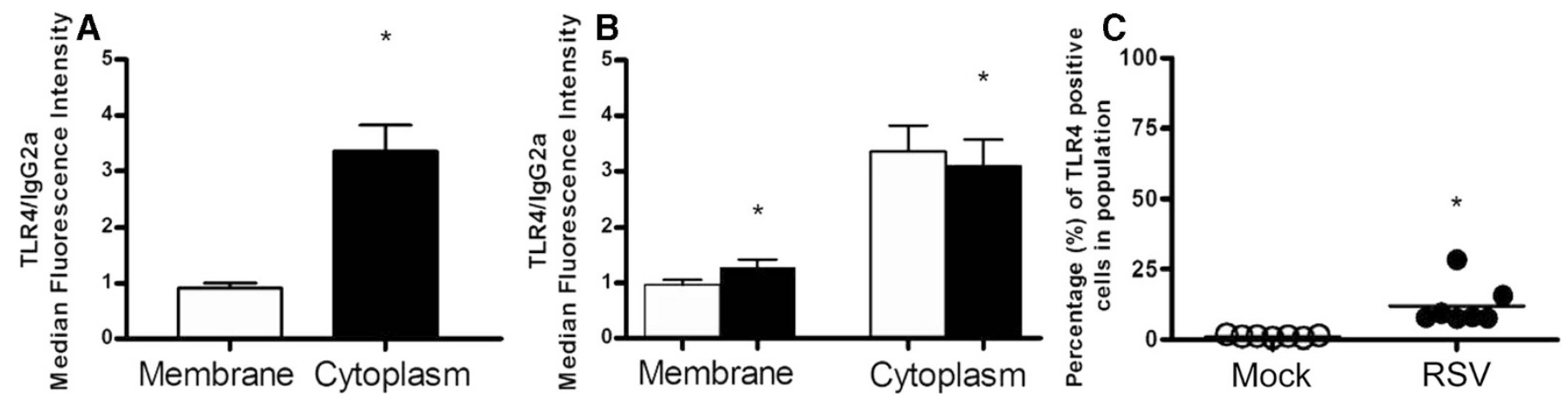

Figure 2. Flow cytometry analysis of TLR4 expression on 9HTEo cells infected with RSV for $24 \mathrm{~h}$. (A) TLR4 mainly expressed in cytoplasm of un-infected 9HTEo cells. $n=8, * p<0.001$. (B) RSV infection up-regulated the membrane TLR4 level and decreased the cytosolic expression of TLR4 in 9HTEo cells. $n=10$ and $8, * p<0.05$. MOCK $(\square)$, RSV $(\square)$. (C) Percentage of TLR4-positive cells was significantly increased after RSV infection, as shown by membrane staining. $n=7, * p<0.05$. Values expressed as mean \pm SEM.

Taken together, the results indicated that the increased TLR4 protein expression on surface and diminished cytoplasmic expression in RSV-primed cells was not only a dynamic localization change. Our quantitative PCR finding of TLR4 up-modulation in the transcriptional step was corroborated by the increasing events of TLR4 in the posttranscription step. 

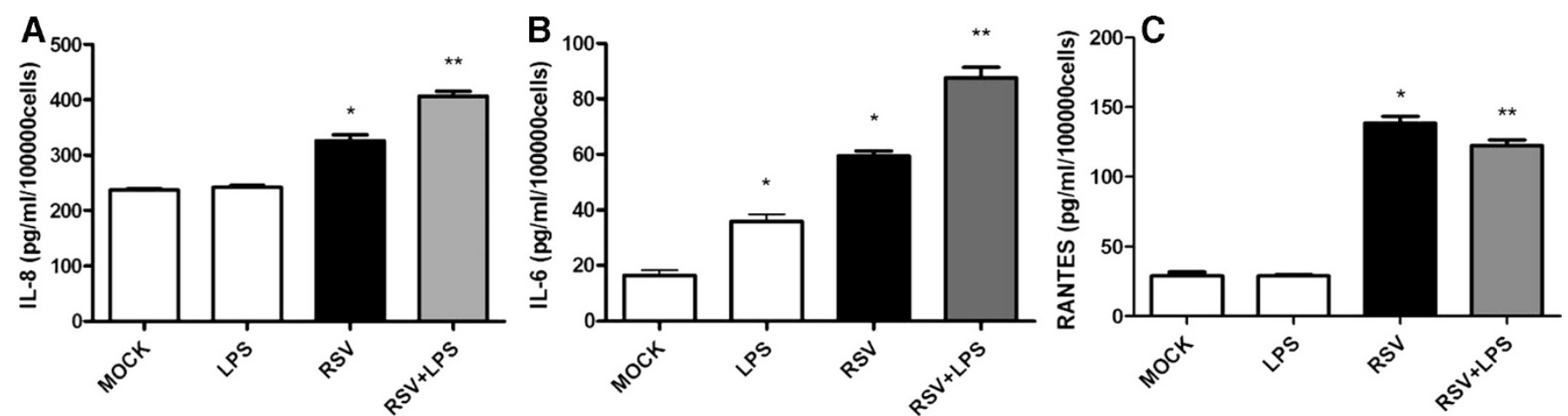

Figure 3. LPS-induced-IL-8, IL-6, and RANTES production in RSV-infected cells. (A) LPS alone did not stimulate IL-8 expression, but it up-regulated its expression significantly in RSV infected cells. (B) Significant increase of IL-6 was detected in LPS stimulated RSV-infected cells. (C) LPS had no effect on RANTES expression, but it down-regulated its expression in RSV-infected cells. Values expressed as mean \pm SEM, $n=3-4, * p<0.05 v s$. MOCK, $* * p<$ 0.05 vs. RSV.

The dynamic shift hypothesis might not entirely explain the remaining $22 \%$ of elevated surface TLR4 expression. This TLR4 protein expression pattern from level to localization was caused by RSV, which might be the main reason for the increased percentage of membrane-TLR4 positive cells, consisting with the results we demonstrated above.

IL-6, IL-8, and RANTES production in LPS-epithelial system and RSV-epithelial-LPS system. Endotoxin, or its purified derivative LPS, a cell wall component of Gramnegative bacteria, is a potent proinflammatory constituent continuously shedding into the environment, which is important in the pathogenesis of airway inflammatory diseases such as asthma. To study whether LPS-induced cytokine or chemokine production in noninfected airway epithelial cells, we chose chemokine CXC family member IL-8, IL-6 cytokine and the chemokine CCL family member RANTES as examples, as they also play a pivotal role in airway immune response to RSV infection $(15,19)$. We found that incubation with $50 \mu \mathrm{g} / \mathrm{mL}$ LPS (the dose choosing data were not shown) slightly up-regulated IL-6 production in 9HTEo cells (Fig. 3B). LPS had no effect on IL-8 or RANTES secretion (Fig. $3 A$ and $C$ ). Based on our data of TLR4 expression, we hypothesized that the increase of TLR4 expression in RSV-infected cells enhanced the TLR4 signaling triggered by LPS, which might then result in further production of cytokine and chemokine. Data in Figure 3 showed that RSV-infection induced a significant increase of IL-8, IL-6, and RANTES (Fig. 3A, $B$, and $C$ ). The concomitant LPS stimulation to RSV-infected cells caused significantly increased IL-8 and IL-6 secretions (Fig. $3 A$ and $B$ ), suggesting that responsiveness to LPS as proinflammatory stimulation was enhanced in the RSVinfected cells compared with un-infected cells. We proposed that TLR4 might be involved in these responses. Interestingly, we consistently detected the down-regulation of RANTES in RSV-infected cells treated by LPS (Fig. 3C).

Correlation of TLR4 pathway and IL-8, IL-6, not RANTES secretion profile by LPS in RSV-infected epithelial cells. We further determined the involvement of TLR4 by using HTA125, a TLR4 neutralizing antibody, to observe whether HTA125 could block the effect of LPS on the RSVinfected cells. After stimulation by LPS, RSV-infected cells were incubated with HTA125 for $48 \mathrm{~h}$. Treating the RSV infected cells with HTA125 completely reversed the upregulatory effects of LPS on IL-6 production (Fig. 4B). The induction of IL- 8 production by LPS was only partially reversed, but the decrease was statistically significant (Fig. $4 A$ ). RANTES secretion was not affected by HTA125 incubation (Fig. 4C). To confirm the involvement of TLR4 in IL-8 and IL-6 secretion, we performed another series of TLR4 targeting RNA interference experiments. First, we evaluated the ability of TLR4-specific siRNA to reduce expression of the corresponding mRNA and protein. After 24 and $48 \mathrm{~h}$ transfection, TLR4-specific siRNA clearly inhibited 69.3 and $90.8 \%$ TLR4 mRNA expression by quantitative PCR detection, 46 and $78 \%$ expression of TLR4 protein by flow cytometry detection, and nonsilencing siRNA failed to inhibit TLR4 mRNA and protein expression (data were not shown). Second, after 24 h TLR4specific siRNA and control-siRNA transfection, we challenged epithelial cells with RSV and LPS. IL-8 induced by LPS was found to be partially decreased, and IL- 6 induced by LPS was almost inhibited in TLR4-siRNA treated epithelial cells, which was similar to HTA125, whereas the controlsiRNA had no effect on IL-8 and IL-6 expression (Fig. $4 D$ and $E$ ). Thus, our observations suggested that TLR4 was important for LPS-induced IL-6 and IL-8, not RANTES in RSV-infected epithelial cells. Comparing to mock-infected cells, HTA125 alone had no effect on IL-6 and RANTES secretion, but significantly decreased IL-8 production (Fig. $3 A$ ), which was also investigated in the TLR4-siRNA treated 9HTEo cells (Fig. 4A). Considering the endotoxin contamination of our system was below $0.25 \mathrm{ng} / \mathrm{mL}$, and serum-free medium was used throughout the ELISA experiments, we supposed that the autocrine IL-8 synthesis of 9HTEo epithelial cell line might be associated with TLR4 pathway.

\section{DISCUSSION}

The impact of RSV on epithelial TLRs expression in previous studies only discussed TLR4 and TLR3, which are implicated in the RSV infection by recognition of RSV-F protein and double-stranded RNA, respectively (13, 20, and 21). To the best of our knowledge, this is the first study to 

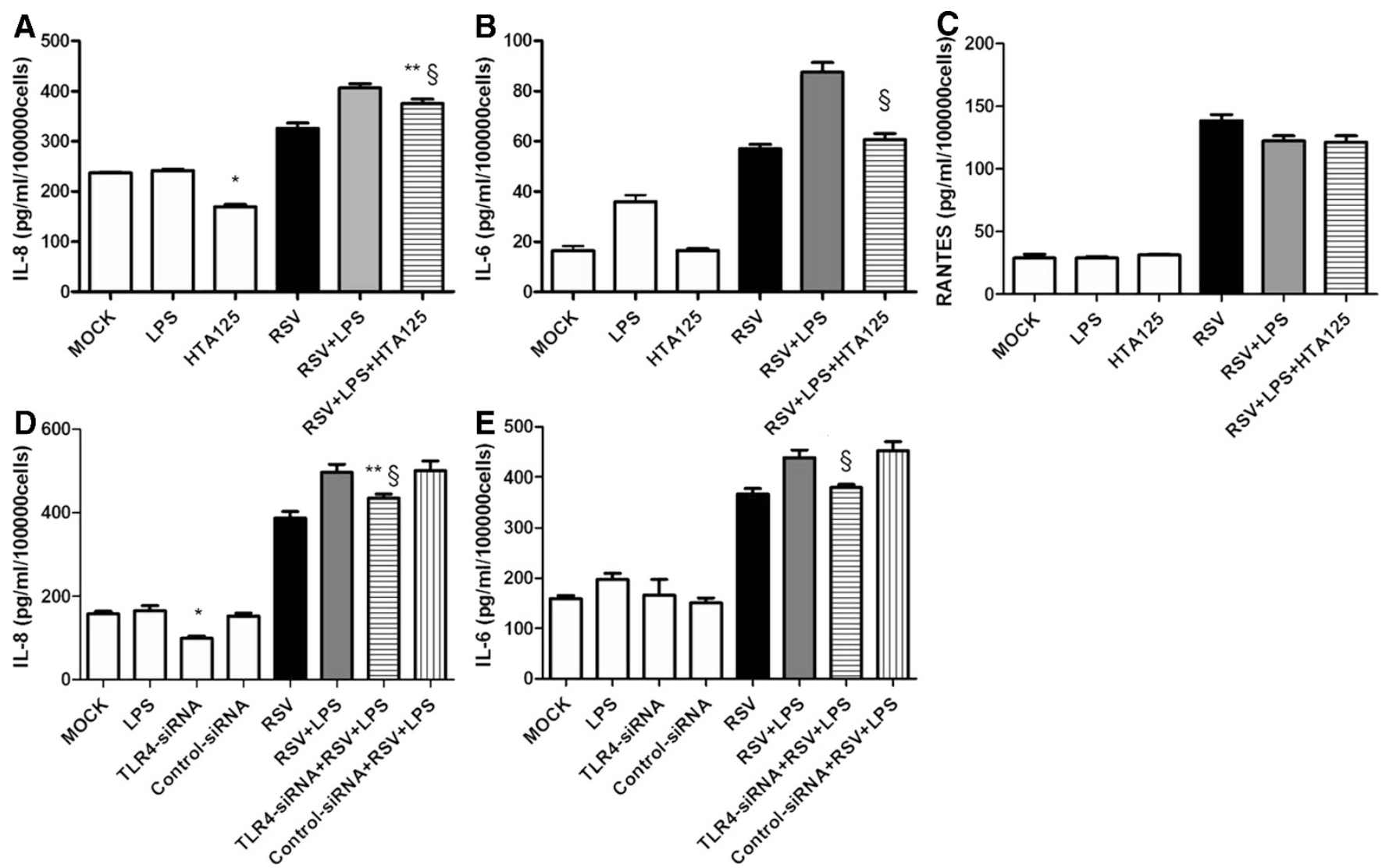

Figure 4. Blocking of TLR4 by a TLR4 neutralizing antibody (HTA125 $20 \mu \mathrm{g} / 10^{5}$ cells) reduced the LPS-induced IL-8 (A) and IL-6 (B) production but have no effect on RANTES $(C)$. LPS-induced production of IL-8 $(D)$ and IL-6 $(E)$ in RSV-infected 9HTEo cells were inhibited by TLR4-specific siRNA (150 nM/10 5 cells). Values expressed as mean $\pm \mathrm{SEM}, * p<0.05 v s$. MOCK, $* * p<0.05 v s$. RSV, $\$ p<0.05 v s$. RSV+LPS.

demonstrate that TLR1-10 mRNA expressions of 9HTEo epithelial cell could be up-regulated by RSV in a short phase of infection, and that the pattern was characterized by the higher mRNA expression of TLR4 and TLR8. Although TLR4 and TLR8 mRNA was higher at baseline expression in un-infected 9HTEo cells, we proposed the marked changes of these two TLRs might also be attributed to their sensing of RSV-F protein and ssRNA in the presence of RSV replication. The virus replication event was indispensable for its regulation of TLRs expression, and might be explained by the mimic effect of numerous viral intermediate products as TLRs agonists during RSV replication. The up-regulation of the whole TLRs system in virus-primed epithelial cells without exact PAMP recognition might not only mean a start of disastrous inflammatory cascades by these TLRs signaling in RSV infection alone, but may also cause long-term inflammation if some PAMPs stimulated these abnormally sensitive epithelial cells through TLRs pathway at a precise time. It is suggested by the observation that enhanced IL-8 production was found in RSV-challenged A549 cells after LPS and polyriboinosinic:polyribocytidylic acid (polyIC) simulations $(20,21)$. However, not all the TLRs pathways could be functional because other reports have shown that RSV-infected A549 cells have no IL-8 response to single-stranded RNA and CpG DNA stimulation $(21,22)$. Further, studies are needed to identify the function of these enhanced TLRs pathways.
TLR4 protein was identified as the recognition receptor of LPS and RSV F protein (5). Several authors examined the inflammatory role of TLR4 signaling in RSV infection through in vivo and in vitro experimental models, and two articles validated the presence of TLR4 on cell surface using flow cytometry. Gagro et al. (23) showed that TLR4 expression on $\mathrm{CD} 14^{+}$monocyte was significantly higher in infants with RSV bronchiolitis. Monick et al. (13) showed that lung alveolar type II epithelial cell line A549 infected by RSV was more sensitive to endotoxin exposure because of the RSV mediated up-regulation of TLR4 protein membrane expression. Herein, we used 9HTEo, another epithelial cell line that originated from human tracheal epithelial cells, to investigate the capability of RSV on TLR4 protein. The distribution of TLR4 protein on 9HTEo cells was mainly in the cytoplasm with little expression on the cell-surface membrane, consistent with previous observations in other epithelial cell line or primary epithelial culture (12). In RSV-infected epithelial cells, there was moderate TLR4 up-regulation on cell surfaces and corresponding down-regulation in the cellular cytoplasm. We proposed that the increasing surface expression of TLR4 protein was due to TLR4 protein redistribution from cytoplasm to membrane and elevated TLR4 mRNA transcription. Our study further confirmed the up-regulation of TLR4 expression on epithelial cell surfaces by RSV and was the first to show the altered cytosolic location of epithelial TLR4 subse- 
quent to RSV infection. Surface TLR4 changes by RSV might be functional to render infected-epithelial cells sensitive to TLR4 agonist LPS stimulation. Compared with Monick's protocol, we not only evaluated whether RSV-induced epithelial cells could respond to LPS stimulation as his group did, but also explored what kind of cytokine-chemokine secretion profile RSV-infected cells might display, such as IL-6, IL-8, and RANTES, which are major mediators correlated with the severity of RSV disease (24). In our studies, LPS as a TLR4 agonist induced higher secretions of IL-6 and IL-8, and decreased RANTES production in RSV-infected epithelial cells. A similar IL-8 response has been reported in RSV primingA549 epithelial cells, and IL-6 response in infected epithelial cells was similarly observed in LPS-activated monocytes $(13,25)$. RANTES secretion of infected epithelial cells was distinct from IL-6 and IL-8. LPS stimulation could not trigger RANTES release as it did in monocytes; in fact, it acted conversely as a glucocorticoid to decrease the RANTES expression. The molecular mechanism, for this different phenotype, was not clear, but might be associated with the interfering role of RSV NS protein in interferon regulatory factor-3 (IRF-3) activation, and needs to be further explored in desirable models $(26,27)$.

Besides TLR4, recognition of LPS is associated with nonTLR-related molecules, ranging from integrins such as CD11b/CD18 to chemokine receptors, scavenger receptors, and many others (28). Through TLR4-blocking and TLR4specific RNA interference experiments, we found that TLR4 was necessary for the elevation of IL-6 and partial IL-8 in epithelial cells. This suggested that the TLR4 signaling pathway might participate in the IL-6 production of epithelial cells after RSV infection. Kurt-Jones et al. (5) have reported suppressed IL-6 response in macrophages derived from TLR-4 deficient C57BL10/ScCr mice to RSV challenge. Our data suggested a similar role for TLR4 in epithelial IL-6 response to RSV infection. IL-6 is involved in exacerbation of polymorphonuclear neutrophil leukocyte (PMN)-mediated hyperinflammation by delaying PMN apoptosis, and recently, studies descrbied that dendritic cell (DC)-derived IL-6 is necessary for the blockade of regulatory $\mathrm{T}$ cell (Treg) activity (29-31). So IL-6 induced by epithelial TLR4 pathway is thought to render neutrophil survival, oxidation activity, even inhibition of Treg suppression function, to cause a polarized Th2 response during the infection, all of which would contribute to a long-term inflammatory situation in the RSV disease.

Regarding allergy development, LPS was associated with an increased risk of persistent wheeze during the first year of life, when the incidence of RSV infection was highest (32). We proposed that the cytokine-chemokine secretion profile played an important role in the positive association of LPS with persistent wheezing. Our results suggest that the profile of cytokine and chemokine released by epithelial cells was different between the RSV alone versus the RSV-allergen cooperative condition. A different secretion pattern could influence immune cell types trafficking to inflammatory sites, and the ability of some resident cells to induce a different inflammatory response. This may potentially cause current wheezing or create a different immunologic memory to contribute to the risk of RAD. In light of our results, it would be particularly interesting to determine what other cytokine and chemokine TLR4 signaling might induce in RSV infection. Studies determining whether TLR4 polymorphisms is related to the RAD post-RSV bronchiolitis would no doubt be a better way to evaluate our hypothesis that TLR4-mediated inflammatory mediator profile was one of the important factors to the clinical outcome.

In summary, our findings provided evidence that RSV up-regulated TLR1-10 mRNA, and TLR4 played an important role in the IL- 6 response of airway epithelial cell in an RSV-LPS cooperative system. Further efforts also need to confirm what other $\mathrm{T}$ helper-related cytokine productions are induced by TLR4 signaling, and each contribution to clinical consequences for the purpose of effectible therapeutics for RSV-induced RAD.

Acknowledgments. We thank Hua-wei Mao (M.D. Candidate) at the University of Hong Kong, Yu Deng (Ph.D. Candidate), Wei Liu, and Wen-fei $\mathrm{Xu}$ at the Immunologic Laboratory for technical support.

\section{REFERENCES}

1. Martinez FD 2005 Heterogeneity of the association between lower respiratory illness in infancy and subsequent asthma. Proc Am Thorac Soc 2:157-161

2. Sha Q, Truong-Tran AQ, Plitt JR, Beck LA, Schleimer RP 2004 Activation of airway epithelial cells by toll-like receptor agonists. Am J Respir Cell Mol Biol 31:358-364

3. Medzhitov R 2001 Toll-like receptors and innate immunity. Nat Rev Immunol $1: 135-145$

4. Takeda K, Kaisho T, Akira S 2003 Toll-like receptors. Annu Rev Immunol $21: 335-376$

5. Kurt-Jones EA, Popova L, Kwinn L, Haynes LM, Jones LP, Tripp RA, Walsh EE, Freeman MW, Golenbock DT, Anderson LJ, Finberg RW 2000 Pattern recognition receptors TLR4 and CD14 mediate response to respiratory syncytial virus. Nat Immunol 1:398-401

6. Alexopoulou L, Holt AC, Medzhitov R, Flavell RA 2001 Recognition of doublestranded RNA and activation of NF-kappa B by Toll-like receptor 3. Nature 413:732-738

7. Hemmi H, Kaisho T, Takeuchi O, Sato S, Sanjo H, Hoshino K, Horiuchi T, Tomizawa H, Takeda K, Akira S 2002 Small anti-viral compounds activate immune cells via the TLR7 MyD88-dependent signaling pathway. Nat Immunol 3:196-200

8. Hemmi H, Takeuchi O, Kawai T, Kaisho T, Sato S, Sanjo H, Matsumoto M, Hoshino K, Wagner H, Takeda K, Akira S 2000 A Toll-like receptor recognizes bacterial DNA. Nature 408:740-745, comment 659-660

9. Holtzman MJ, Shornick LP, Grayson MH, Kim EY, Tyner JW, Patel AC, Agapov E, Zhang Y 2004 Hit-and-run effects of paramyxoviruses as a basis for chronic airway disease. Pediatr Infect Dis J 23:S235-S245

10. Guillot L, Le Goffic R, Bloch S, Escriou N, Akira S, Chignard M, Si-Tahar M 2005 Involvement of toll-like receptor 3 in the immune response of lung epithelial cells to double-stranded RNA and influenza A virus. J Biol Chem 280:5571-5580

11. Greene CM, Carroll TP, Smith SG, Taggart CC, Devaney J, Griffin S, O'neill SJ, McElvaney NG 2005 TLR-induced inflammation in cystic fibrosis and non-cystic fibrosis airway epithelial cells. J Immunol 174:1638-1646

12. Greene CM, McElvaney NG 2005 Toll-like receptor expression and function in airway epithelial cells. Arch Immunol Ther Exp (Warsz) 53:418-427

13. Monick MM, Yarovinsky TO, Powers LS, Butler NS, Carter AB, Gudmundsson G, Hunninghake GW 2003 Respiratory syncytial virus up-regulates TLR4 and sensitizes airway epithelial cells to endotoxin. J Biol Chem 278:53035-53044

14. Proud D 2003 Biology of epithelial cells. In: Adkinson NFJ, Yunginger JW, Busse WW, Bochner BS, Holgate ST, Simons FER (eds) Middleton's Allergy: Principles and Practice. Philadelphia: Mosby, pp 373-384

15. Law HK, Cheung CY, Ng HY, Sia SF, Chan YO, Luk W, Nicholls JM, Peiris JS, Lau YL 2005 Chemokine up-regulation in SARS-coronavirus-infected, monocytederived human dendritic cells. Blood 106:2366-2374

16. Stecenko AA, King G, Torii K, Breyer RM, Dworski R, Blackwell TS, Christman JW, Brigham KL 2001 Dysregulated cytokine production in human cystic fibrosis bronchial epithelial cells. Inflammation 25:145-155

17. Heil F, Hemmi H, Hochrein H, Ampenberger F, Kirschning C, Akira S, Lipford G, Wagner H, Bauer S 2004 Species-specific recognition of single-stranded RNA via Toll-like receptor 7 and 8. Science 303:1526-1529

18. Guillot L, Medjane S, Le-Barillec K, Balloy V, Danel C, Chignard M, Si-Tahar M 2004 Response of human pulmonary epithelial cells to lipopolysaccharide involves 
Toll-like receptor 4 (TLR4)-dependent signaling pathways: evidence for an intracellular compartmentalization of TLR4. J Biol Chem 279:2712-2718

19. Yoon JS, Kim HH, Lee Y, Lee JS 2007 Cytokine induction by respiratory syncytial virus and adenovirus in bronchial epithelial cells. Pediatr Pulmonol 42:277-282

20. Rudd BD, Burstein E, Duckett CS, Li X, Lukacs NW 2005 Differential role for TLR3 in respiratory syncytial virus-induced chemokine expression. J Virol 79:3350-3357

21. Groskreutz DJ, Monick MM, Powers LS, Yarovinsky TO, Look DC, Hunninghake GW 2006 Respiratory syncytial virus induces TLR3 protein and protein kinase R, leading to increased double-stranded RNA responsiveness in airway epithelial cells. J Immunol 176:1733-1740

22. Schlender J, Hornung V, Finke S, Günthner-Biller M, Marozin S, Brzózka K, Moghim S, Endres S, Hartmann G, Conzelmann KK 2005 Inhibition of toll-like receptor 7- and 9-mediated alpha/beta interferon production in human plasmacytoid dendritic cells by respiratory syncytial virus and measles virus. J Virol 79:55075515

23. Gagro A, Tominac M, Krsulović-Hresić V, Bace A, Matić M, Drazenović V Mlinarić-Galinović G, Kosor E, Gotovac K, Bolanca I, Batinica S, Rabatić S 2004 Increased Toll-like receptor 4 expression in infants with respiratory syncytial virus bronchiolitis. Clin Exp Immunol 135:267-272

24. Schaller M, Hogaboam CM, Lukacs N, Kunkel SL 2006 Respiratory viral infection drive chemokine expression and exacerbate the asthmatic response. J Allergy Clin Immunol 118:295-302

25. Asai K, Hiki N, Mimura Y, Ogawa T, Unou K, Kaminishi M 2001 Gender differences in cytokine secretion by human peripheral blood mononuclear cells: role of estrogen in modulating LPS-induced cytokine secretion in an ex vivo septic model. Shock 16:340-343

26. Fokkema SJ, Loos BG, van der Velden U 2003 Monocyte-derived RANTES is intrinsically elevated in periodontal disease while MCP-1 levels are related to inflammation and are inversely correlated with IL-12 levels. Clin Exp Immunol 131:477-483

27. Spann KM, Tran KC, Collins PL 2005 Effects of nonstructural proteins NS1 and NS2 of human respiratory syncytial virus on interferon regulatory factor 3,NFkappaB,and proinflammatory cytokines. J Virol 79:5353-5362

28. Janssens S, Beyaert R 2003 Role of Toll-like receptors in pathogen recognition. Clin Microbiol Rev 16:637-646

29. Asensi V, Valle E, Meana A, Fierer J, Celada A, Alvarez V, Paz J, Coto E, Carton JA, Maradona JA, Dieguez A, Sarasúa J, Ocaña MG, Arribas JM 2004 In vivo interleukin-6 protects neutrophils from apoptosis in osteomyelitis. Infect Immun 72:3823-3828

30. Detournay O, Mazouz N, Goldman M, Toungouz M 2005 IL-6 Produced by type I IFN DC controls IFN- $\gamma$ production by regulating the suppressive effect of $\mathrm{CD}^{+}$ $\mathrm{CD} 25^{+}$regulatory T cells. Hum Immunol 66:460-468

31. Wan S, Xia C, Morel L 2007 IL-6 produced by dendritic cells from lupus-prone mice inhibits CD4+ CD25 + T cell regulatory functions. J Immunol 178:271-279

32. Park JH, Gold DR, Spiegelman DL, Burge HA, Milton DK 2001 House dust endotoxin and wheeze in the first year of life. Am J Respir Crit Care Med $163: 322-328$ 